\title{
Sensitivity of Continuous and Discrete Plant and Soil Water Status Monitoring in Peach Trees Subjected to Deficit Irrigation
}

\author{
David A. Goldhamer ${ }^{1}$ \\ Department of Land, Air, and Water Resources, University of California, Davis, CA 95616 \\ Elias Fereres $^{2}$ \\ IAS-CSIC and University of Cordoba, Apdo 4084, 14080 Cordoba, Spain \\ Merce Mata ${ }^{3}$ and Joan Girona ${ }^{4}$ \\ Institut de Recerca I Tecnologia Agroalimentaries, Lleida, Spain \\ Moshe Cohen ${ }^{5}$ \\ Institut de Recerca I Tecnologia Agroalimentaries, Cabrils, Spain
}

\begin{abstract}
ADDitional INDEX wORDs. water stress, deficit irrigation, trunk diameter fluctuations, linear variable displacement transducer (LVDT), plant water potential, photosynthesis
\end{abstract}

\begin{abstract}
ABSTRACт. To characterize tree responses to water deficits in shallow and deep rooted conditions, parameters developed using daily oscillations from continuously measured soil water content and trunk diameter were compared with traditional discrete monitoring of soil and plant water status in lysimeter and field-grown peach trees [Prunus persica (L.) Batsch ' $O$ 'Henry']. Evaluation occurred during the imposition of deficit irrigation for 21 days followed by full irrigation for 17 days. The maximum daily available soil water content fluctuations (MXAWCF) taken at any of the four monitored root zone depths responded most rapidly to the deficit irrigation. The depth of the MXAWCF increased with time during the deficit irrigation. Differences relative to a fully irrigated control were greater in the lysimeter than the field-grown trees. Minimum daily trunk diameter (MNTD) and maximum daily trunk shrinkage (MDS) responded sooner than midday stem water potential (stem $\Psi$ ), predawn or midday leaf water potential (predawn leaf $\Psi$ and leaf $\Psi$ ), or photosynthesis (A). Parameters based on trunk diameter monitoring, including maximum daily trunk diameter (MXTD), correlated well with established physiological parameters of tree water status. Statistical analysis of the differences in the measured parameters relative to fully irrigated trees during the first 10 days of deficit irrigation ranked the sensitivity of the parameters in the lysimeter as MXAWCF > MNTD $>$ MDS $>$ MXTD $>$ stem $\Psi=A=$ predawn leaf $\Psi=$ leaf $\Psi$. Equivalent analysis with the field-grown trees ranked the sensitivity of the parameters as MXAWCF $>$ MNTD $>$ MDS $>$ stem $\Psi=$ leaf $\Psi=$ MXTD = predawn leaf $\Psi>$ A. Following a return to full irrigation in the lysimeter, MDS and all the discrete measurements except A quickly returned to predeficit irrigation levels. Tree recovery in the field-grown trees was slower and incomplete due to inadequate filling of the root zone. Fruit size was significantly reduced in the lysimeter while being minimally affected in the field-grown trees. Parameters only available from continuous monitoring hold promise for improving the precision of irrigation decision-making over the use of discrete measurements.
\end{abstract}

Many approaches for measuring soil water status to guide irrigation decision are used to optimize crop yields while conserving water (Martin et al., 1990). Plant water status monitoring can also be used for timing irrigation in herbaceous species (Grimes and Yamada, 1982; Hsiao, 1990) and in deciduous fruit trees (Fereres and Goldhamer, 1990) although it is much less widely practiced than soil water assessment. Until recently, most of these approaches involved discrete measurements in both space and time. Interpretation of these data usually requires comparison with previously established

Received for publication 21 Sept. 1998. Accepted for publication 12 Apr. 1999. This work was funded under the auspices of the Univ. of California/Institut de Recerca i Tecnologia Agroalimentaries (IRTA) Cooperative Agreement. We gratefully acknowledge the support of Associate Vice President-Programs Henry Vaux, Division of Agriculture and Natural Resources, Univ. of California, and Director Josep Tarrago IRTA. We also appreciate the technical support of Scott Johnson, Dept. of Pomology, Univ. of California, and the field assistance of Ana Cohen and Dan Howes. The cost of publishing this paper was defrayed in part by the payment of page charges. Under postal regulations, this paper therefore must be hereby marked advertisement solely to indicate this fact.

${ }^{1}$ Water management specialist.

${ }^{2}$ Director and professor.

${ }^{3}$ Research associate.

${ }^{4}$ Research leader.

${ }^{5}$ Research scientist. threshold values whose approach signals the need for an irrigation. The timely detection of critical soil and plant water status is directly related to the monitoring frequency. Thus, the precision of using discrete measurements depends on the amount of labor allocated for monitoring which, in turn, is influenced by real or perceived economic benefits of the soil or plant water assessment program.

Advances in electronics and equipment robustness have enabled continuous monitoring of soil water status. Electro-tensiometers and resistance probes (McDonnell, 1993; Seyfried, 1993), time domain reflectometry systems (Dalton, 1992), and capacitance probes (Paltineau and Starr, 1997) can record data every few minutes giving the irrigation manager knowledge of soil water status with depth and time at the installation point in the field. In addition to the traditional soil water indicators such as available soil moisture profiles, continuous measurements can be used to determine daily extraction and wetting patterns that better reflect the dynamic nature of soil water (Ley, 1994).

The usefulness of instruments to continuously measure plant water status has been limited. Leaf $\Psi$ has been estimated with thermocouple psychrometers (Savage et al., 1983) but they tend to suffer operational and logistical problems in the field environment (Hsiao, 1990). Changes in stem diameter were found to be well correlated with leaf $\Psi$ in cotton (Huck and Klepper, 1976; Klepper 
et al., 1971). The linear variable displacement transducer (LVDT) can continuously and accurately monitor stem diameter but until recently was prone to problems in the field (So et al., 1979). Recent improvements in LVDT robustness and data acquisition systems make the use of this instrument more feasible (Huguet et al., 1992).

This research was undertaken to compare the sensitivity of a variety of devices to detect changes in soil and plant water status during the imposition of and recovery from water deficits in trees with lysimeter-constrained and unrestricted root systems. We focused on evaluating the sensitivity of parameters only available using continuous monitoring, such as daily fluctuations, relative to traditional discrete estimates of soil and plant water status. We hypothesized that the shallow, restricted root system of the lysimeter trees would elicit responses to water deficits, such as changing physiological responses without apparent changes in leaf water status, which would differ from those of the field-grown trees (Gowing et al., 1990).

\section{Materials and Methods}

SITE AND IRRIGATION REgIMES. This work was conducted in the summer of 1996 in an orchard of 8-year-old, late maturing peach trees [Prunus persica (L.) Batsch 'O'Henry'] at the University of California Kearney Agricultural Center in Parlier, Calif. The orchard occupied a field of 1.13 ha, tree spacing was $4.9 \times 1.8 \mathrm{~m}$, and the training system was a perpendicular V. The soil is a deep Hanford sandy loam (Typic Xerorrthents) with a bulk density of $\approx 1.6 \mathrm{~g} \cdot \mathrm{cm}^{-3}$ and a volumetric water holding capacity of $\approx 0.10$ $\mathrm{cm}^{3} \cdot \mathrm{cm}^{-3}$. The upper limit of soil water storage (field capacity) varied between $0.17 \mathrm{~cm}^{3} \cdot \mathrm{cm}^{-3}$ in the surface layers to $0.10 \mathrm{~cm}^{3} \cdot \mathrm{cm}^{-3}$ in the sand lenses of the subsoil (Grimes et al., 1975), while the lower limit (permanent wilting point) ranged from 0.034 to $0.030 \mathrm{~cm}^{3} \cdot \mathrm{cm}^{-3}$.

A large $(4 \times 4 \times 2 \mathrm{~m})$ weighing lysimeter planted with two trees, as described in detail by Phene et al. (1991), was located near the center of the field. The lysimeter was packed with soil during installation to obtain bulk densities of $\approx 1.64 \mathrm{~g} \cdot \mathrm{cm}^{-3}$, similar to the surrounding field. It had a usable depth of $\approx 1.7 \mathrm{~m}$. Water tanks located beneath and attached to the lysimeter were used as the water supply for the lysimeter allowing for determination of lysimeter evapotranspiration $\left(\mathrm{ET}_{\mathrm{L}}\right)$ for all but about the $1 \mathrm{~min}$ needed to refill the supply tanks every day. The lysimeter data were collected automatically every hour and their calibrated accuracy was \pm 0.025 $\mathrm{mm}$.

For this experiment, two groups of eight trees of similar size surrounding the lysimeter were selected. Trees in one group (C) were always fully irrigated while the other group(FD) was subjected to the deficit irrigation regime. The deficit irrigation regime was also applied to the lysimeter (LD). All trees were hand thinned early in the season to $\approx 260$ fruit per tree.

Irrigation was with microsprinklers $\left(38 \mathrm{~L} \cdot \mathrm{h}^{-1}\right)$ located $\approx 0.5 \mathrm{~m}$ north of each tree in $\mathrm{C}$ and FD. The circular wetted pattern was $\approx 3.0$ $\mathrm{m}$ in diameter. To prevent spray loss in the lysimeter, rings of $10 \mathrm{drip}$ emitters $\left(2 \mathrm{~L} \cdot \mathrm{h}^{-1}\right)$ were installed around each tree from year 1 . Water meters were used to record irrigation amounts. Irrigation was applied daily with the objective of replenishing the ET losses of the previous day. Irrigation generally began at $0200 \mathrm{HR}$ and was completed in $3 \mathrm{~h}$ in $\mathrm{C}$ and FD. Full replenishment in the lysimeter required up to $6 \mathrm{~h} \cdot \mathrm{d}^{-1}$.

The objective was to begin the experiment with a full soil water profile in $\mathrm{C}$ and partially full profiles in LD and FD. The latter was required due to the water storage capacity of the tree root zone; we anticipated that significant changes in soil and plant water status would occur during the approximate 3-week course of the slow imposition of deficit irrigation only if we reduced the soil water reserve in FD and LD by partially drying the profilebefore the start of the experiment. Therefore, 2 weeks before differential water treatments began, daily irrigation applications were decreased for 5 d in FD and LD from $100 \%$ to $30 \%$ of estimated potential water use.

Before the start of the experiment, the relationship between $\mathrm{ET}_{\mathrm{L}}$ and the reference evapotranspiration $\left(\mathrm{ET}_{\mathrm{o}}\right)$ was determined. Weather data from a nearby CIMIS weather station was used to calculate $\mathrm{ET}_{\mathrm{o}}$ with a modified Penman equation (Snyder and Pruitt, 1989). Full $\left(100 \% \mathrm{ET}_{\mathrm{L}}\right)$ irrigation amounts were applied from 1 to 9 July to the lysimeter and an average crop coefficient $\left(\mathrm{ET}_{\mathrm{L}} / \mathrm{ET}_{\mathrm{o}}\right)$ of 0.826 was obtained. Maximum lysimeter ET $\left(\mathrm{ET}_{\mathrm{LM}}\right)$ was thus estimated as $0.826 \times \mathrm{ET}_{\mathrm{o}}$ during the deficit irrigation period. The irrigation applied to the $\mathrm{C}$ trees before and after the deficit regime was based on $\mathrm{ET}_{\mathrm{o}}$ and a crop coefficient of 1.0 (17\% more than $\left.\mathrm{ET}_{\mathrm{LM}}\right)$ to insure that no water limitation would occur in trees we designated as fully irrigated.

The deficit irrigation started in LD and FD on 10 July with the application of the $75 \% \mathrm{ET}_{\mathrm{LM}}$ through $17 \mathrm{July}, 50 \% \mathrm{ET}_{\mathrm{LM}}$ through 18 July, $25 \% \mathrm{ET}_{\mathrm{LM}}$ through 28 July and no irrigation on 29 to 30 July. On $31 \mathrm{July}, 300 \% \mathrm{ET}_{\mathrm{LM}}$ was applied to LD and FD trees to begin the recovery phase. For the remainder of the recovery phase, irrigation at $100 \% \mathrm{ET}_{\mathrm{LM}}$ was applied to LD and FD trees. Most measurements were terminated on 5 Aug., which was also the harvest date of the LD trees. No rainfall occurred during the experiment.

Measurements. Soil water was monitored with both neutron probe (Hydroprobe 503; Campbell Pacific Corp., Martinez, Calif.) and capacitance (EnviroSCAN, Sentek PTY Ltd., Kent Town, South Australia) techniques. In C and FD, three tubes for each device were installed midway in the row between three sets of trees $(0.91 \mathrm{~m}$ from each tree). Two tubes of each device were installed in the lysimeter on the north and south sides at about the same distance away from the tree trunk. Neutron probe measurements were taken from depths of 0.15 to $3.0 \mathrm{~m}$ in 15 -cm increments every other day. Capacitance probe measurements were recorded every 15 min on a datalogger from the $20,50,80$, and $150 \mathrm{~cm}$ depths. The neutron probe values were gravimetrically calibrated for the experimental soil. Capacitance probe readings were converted to volumetric soil water contents using a relationship developed between the neutron and capacitance probe measurements performed in locations where both sensors were placed within $30 \mathrm{~cm}$ from each other. Cumulative soil water contents for the 0 to $80 \mathrm{~cm}$ soil layer were calculated by assigning the $20,50,80 \mathrm{~cm}$ capacitance probe readings to the 0 to 30 , 30 to 70 , and 70 to $80 \mathrm{~cm}$ soil depth increments, respectively. Available soil water was calculated as the difference between the experimental soil water content values and the permanent wilting point of the soil.

Predawn and midday (1300 to $1400 \mathrm{HR}$ ) leaf $\Psi$ were measured every 2 to $3 \mathrm{~d}$ with a pressure chamber (model 3005; Soil Moisture Equipment Co., Santa Barbara, Calif.). Two leaves from each tree in the C, FD, and LD trees were measured. Midday leaf $\Psi$ was determined on fully sunlit leaves. Stem water $\Psi$ measurements were also made at midday with the same frequency and involved covering two leaves per tree located within the canopy and close to the trunk with a small bag of black polyethylene covered by silver foil for at least $2 \mathrm{~h}$ before the measurement. In all cases, leaves were placed in the chamber within seconds of excision and precautions recommended by Hsiao (1990) were taken to prevent leaf water loss during measurement.

Midday photosynthesis (A) and stomatal conductance $\left(\mathrm{g}_{\mathrm{s}}\right)$ were determined on the same leaves used for leaf $\Psi$ using a portable 
photosynthesis instrument(ADCModelLCA2, ADC BioScientific Ltd, Herts, U.K.) and a steady state porometer (model 1600; LI-COR, Lincoln, Neb.). Since the A and $\mathrm{g}_{\mathrm{s}}$ responses were similar, only the A measurements are reported in detail.

Linear variable displacement transducers (LVDTs; model 2.5 DF; Solartron Metrology, Bagnor Regis, U.K.) were installed on the trunk $0.5 \mathrm{~m}$ above the ground surface on the north side of each of four trees in C and FD and on the two LD trees. They were mounted on holders built of aluminum and INVAR, an alloy comprised of $64 \% \mathrm{Fe}$ and $35 \% \mathrm{Ni}$ that has minimal thermal expansion ( $\mathrm{Li}$ et al, 1989). The LVDTs were covered with silver foil to prevent wetting of the device and the bark by the microsprinklers. Measurements were taken every $30 \mathrm{~s}$ and the datalogger (model CR 10; Campbell Scientific, Logan, Utah) was programmed to report 20-min means. Maximum daily trunk shrinkage (MDS) was determined by taking the difference in daily maximum (MXTD) and minimum (MNTD) trunk diameter values. Throughout the experiment, the LVDTs did not have to be repositioned since the $2500 \mathrm{mV}$ (2.5 $\mathrm{mm}$ ) working range of the datalogger was not exceeded by tree growth.

Fruit diameter on 10 tagged fruit per experimental tree was measured with electronic calipers about every $4 \mathrm{~d}$. A previously determined relationship between fruit diameter and volume (Marsal and Girona, 1997) was used toestimate fruit volume. Fruit on trees notequipped with LVDTs was harvested by hand on 31 July just before the recovery phase. These trees were harvested at this time as fruit was beginning to drop but we did not want the harvest operations to interfere with the continuous monitoring of trunk diameter. The fruit was weighed, mechanically sized, and diameter, fresh, and dry weights determined. The remainder of the trees, including both in the lysimeter, were harvested with the same sampling procedures on 5 Aug.

\section{Results}

INDICATOR RESPONSE TO DEFICIT IRRIGATION. The evolution of four indicators - trunk diameter, predawn leaf $\Psi$, stem $\Psi$, and available soil water in the 0 to $80 \mathrm{~cm}$ layer-during the water stress and recovery periods is shown in Fig. 1 . The first detectable change in response to deficit irrigation was an increased fluctuation in the soil water content in FD and LD, which occurred on 11 July,

Fig. 1. Experimental data with time of (a) trunk diameter that was set to zero on 1 July; vertical gridlines show midnight values for indicated day, (b) predawn and midday leaf water potential, (c) stem water potential, (d) available soil water in 0 to $80 \mathrm{~cm}$ soil layer. Vertical bars are twice the mean SE for measurements through 19 July.
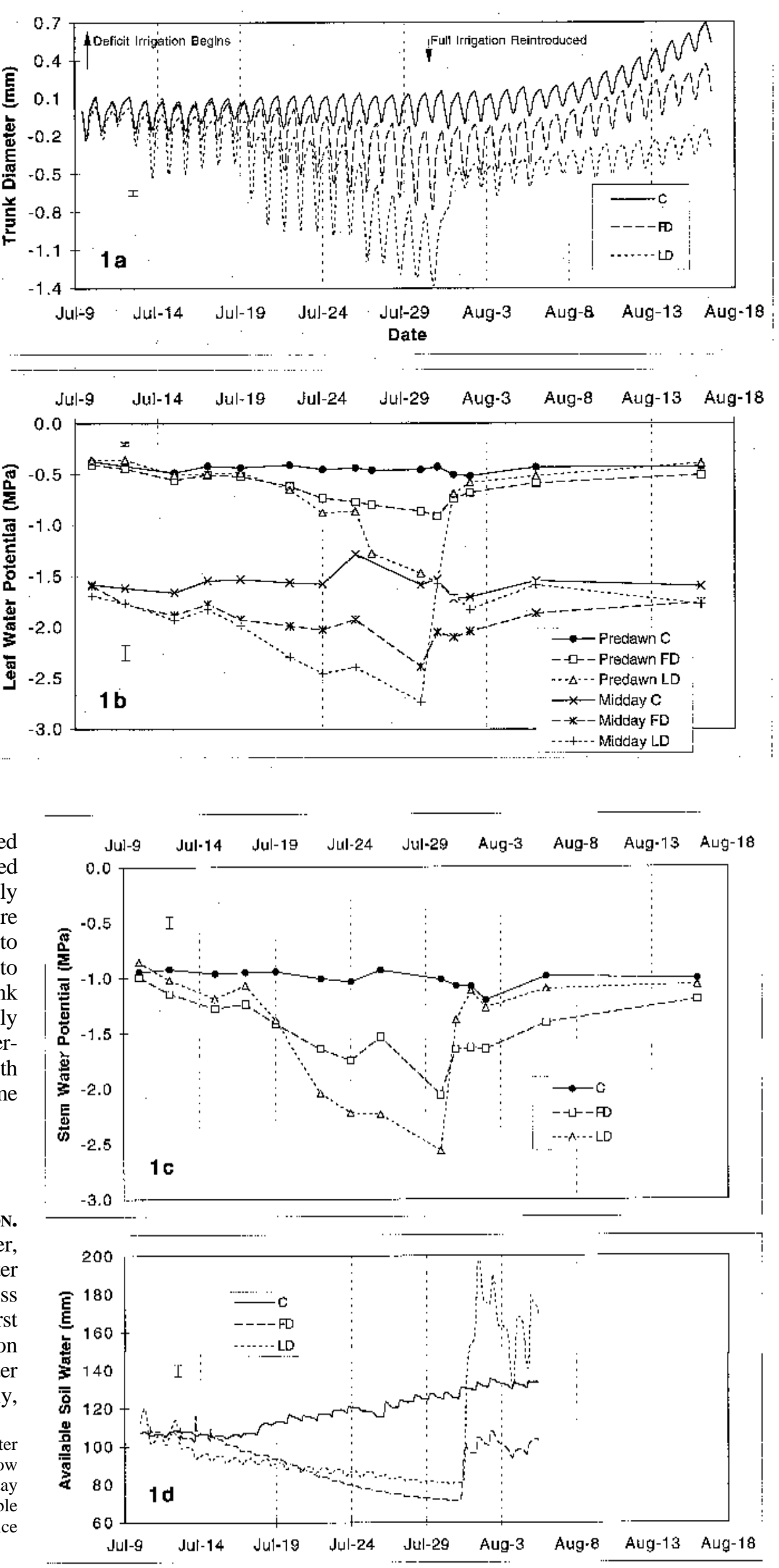

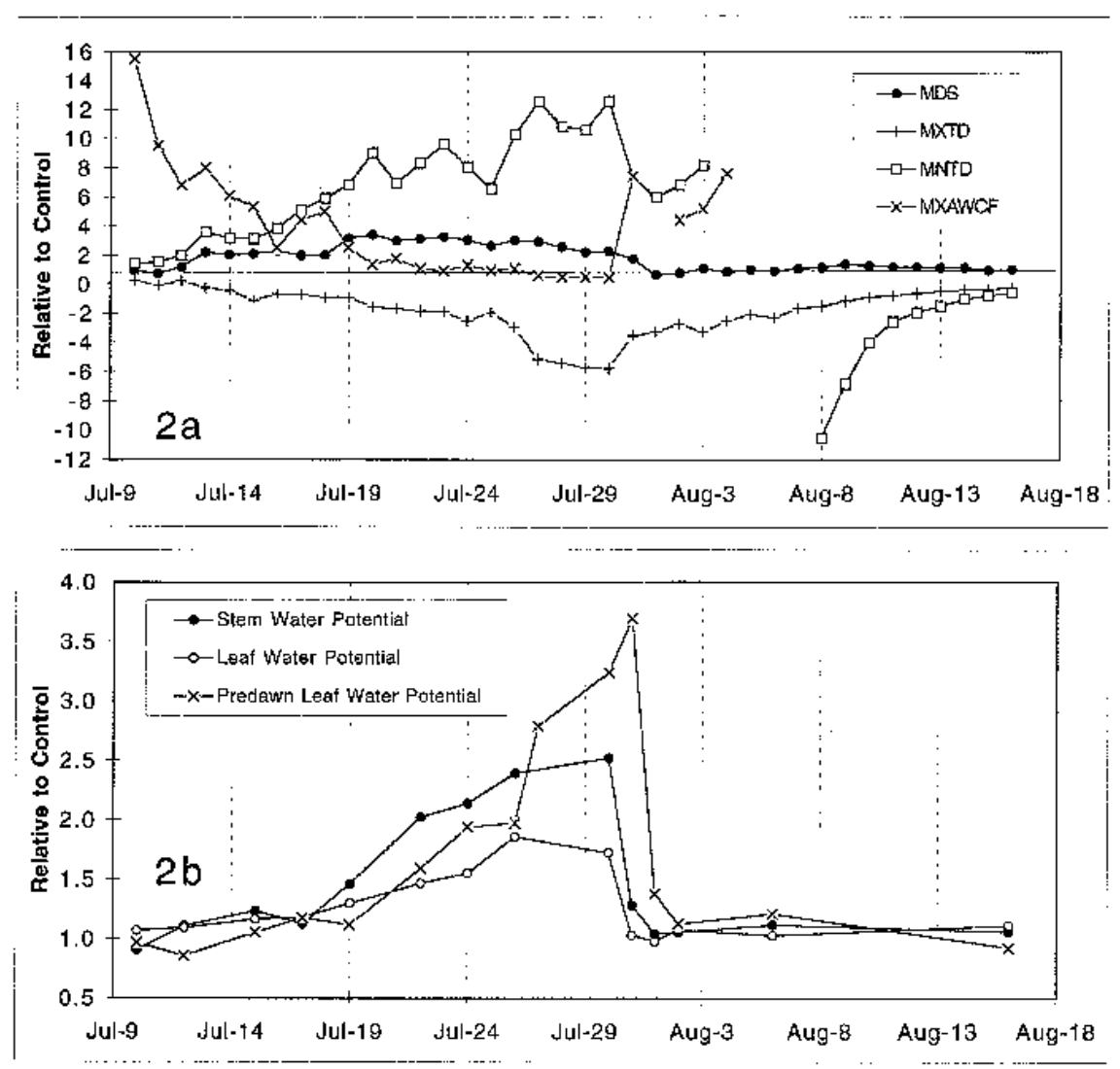

Fig. 2. Deficit irrigation treatment values in the lysimeter (LD) expressed relative to the fully irrigated control (C) with time showing (a) indicators derived from continuous measurements and (b) indicators fromdiscrete measurements. creased in the FD and LD trees relative to the earlier period and relative to the $\mathrm{C}$ trees (Fig. 1d). All other indicators showed irrigation treatment differences which increased with time. Differences between the deficit and fully irrigated trees were greater in the LD than the FD trees.

The recovery period started on 31 July when the trees again were fully irrigated and the indicator trends during that period are also shown in Fig. 1. Trunk diameter fluctuations were substantially reduced within hours of rewatering in FD and LD(Fig. 1a). Notable is the rapid increase in the trunk diameter of the LD trees on 31 July such that the minimum value is difficult to identify; being masked by the dramatic increase in trunk size. The recovery of plant water potentials in the LD trees was nearly complete $2 \mathrm{~d}$ after rewatering while it took the FD trees much longer to recover (Figs. $1 \mathrm{~b}$ and $\mathrm{c}$ and $4 \mathrm{~b}$ ). The final water potential measurements (taken $16 \mathrm{~d}$ after reirrigation began) showed only minor irrigation treatment differences in FD and LD.

In addition to the parameters derived from continuous measurements of trunk diameter (MDS, MXTD, and MNTD) the continuously measured soil water content allowed the maximum daily fluctuation in available soil water content (MXAWCF), defined as the maximum

Fig. 3. Deficit irrigation treatment values in the fieldgrown trees (FD) expressed relative to the fully irrigated control (C) with time showing (a) indicators derived from continuous measurements and $(\mathbf{b})$ indicators from discrete measurements. the day after imposition of deficit irrigation, followed by increased trunk diameter fluctuations which started on 12 July (Fig. 1a). The first measurements of tree water status were taken on that day and failed to detect significant treatment differences. As time progressed, all tree water status parameters in the deficit irrigated trees departed from values measured under full irrigation (Fig. 1b and c). Ten days after the onset of deficit irrigation, all indicators in the LD and FD trees had values that were considerably different than those in the $\mathrm{C}$ trees. Available soil water in the 0 to $80 \mathrm{~cm}$ layer began to decrease $3 \mathrm{~d}$ after the onset of deficit irrigation in LD while $7 \mathrm{~d}$ were required in FD (Fig. 1d).

Treatment differences expanded as water deficits became more acute as a result of both the continuing deficit irrigation and the reduction in its level to $25 \% \mathrm{ET}_{\mathrm{LM}}$ on $20 \mathrm{July}$. Trunk diameter fluctuations increased in FD and LD with the latter trees showing the greatest fluctuations (Fig. 1a). However, as time progressed, trunk diameter fluctuations in the LD trees began to decrease on 27 July and, while always greater than in C, continued to decrease for the duration of the deficit irrigation. This did not occur in the FD trees. As the soil reservoir was being depleted (mean available soil water content decreased), fluctuations in available soil water content de-
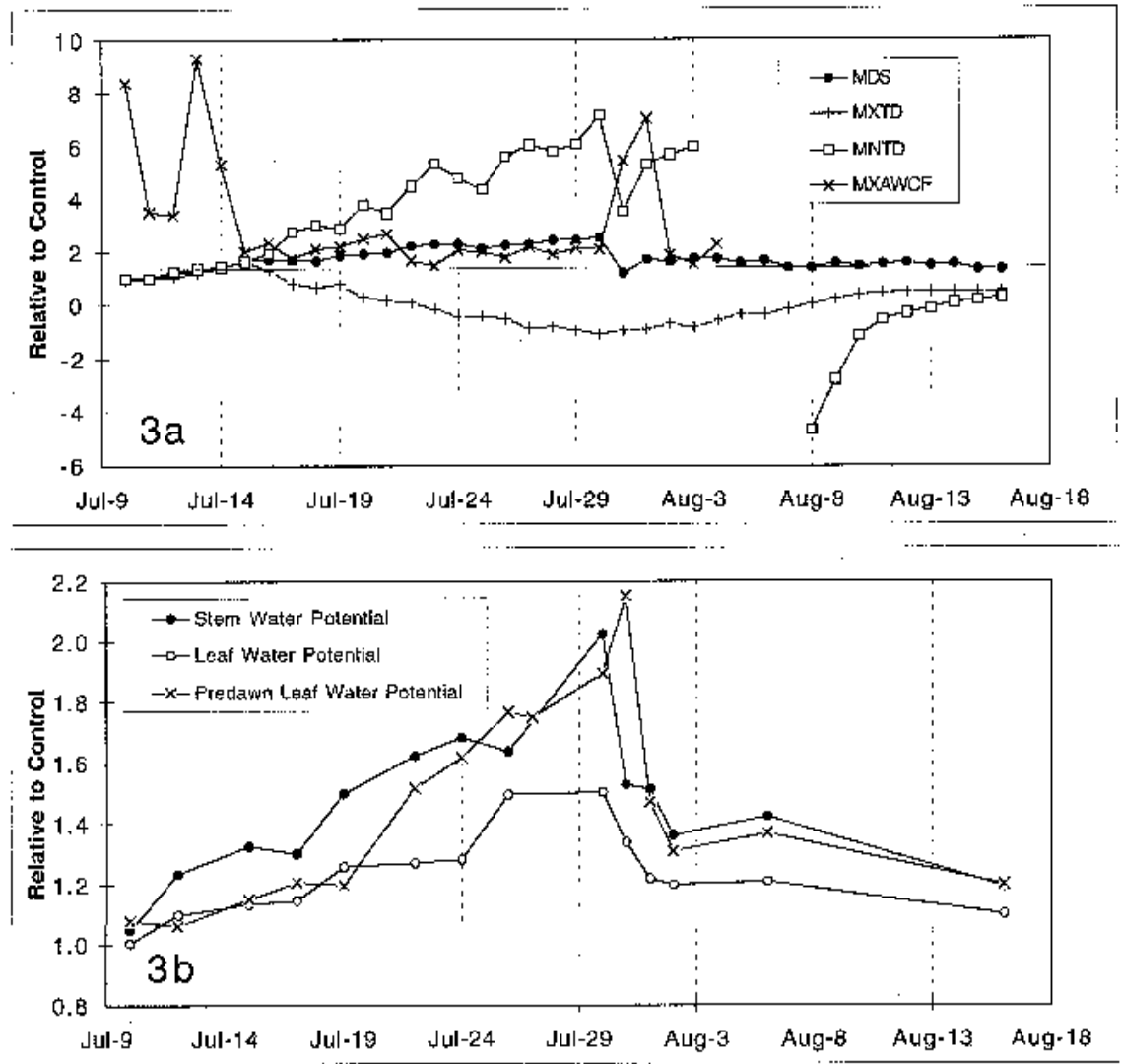


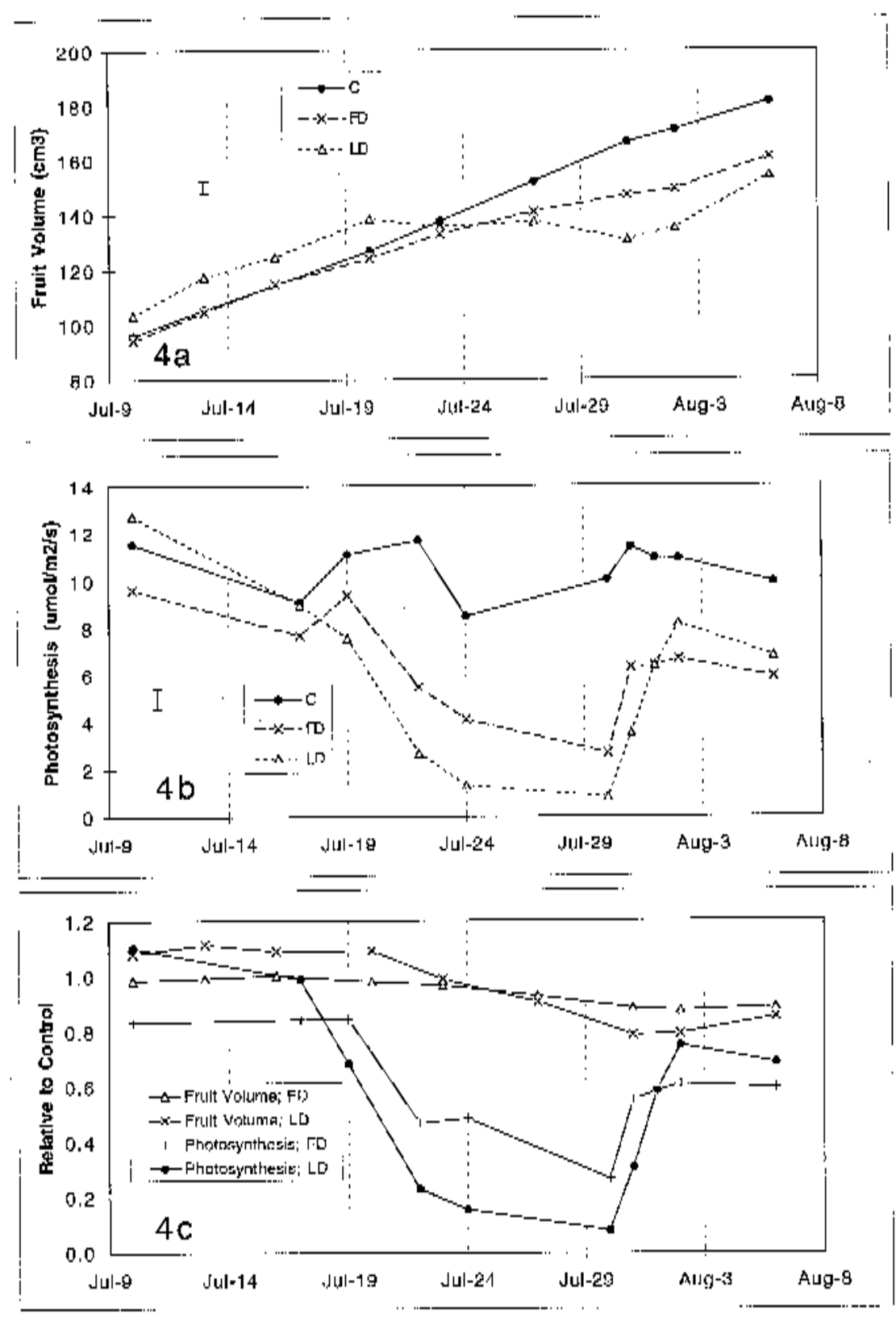

LD and FD trees were calculated relative to the values for the $\mathrm{C}$ trees for the duration of the experiment (Figs. 2a and 3a, respectively). There were large changes in the magnitude of relative MXAWCF and where it occurred in the soil profile during the deficit irrigation period. In FD, for example, the relative MXAWCF from 10 to 16 July occurred in the 0 to 20 and 20 to $50 \mathrm{~cm}$ soil layers and ranged from 8.40 to 2.01. From 17 July to the end of the deficit irrigation period, the greatest relative MXAWCF took place in the 50 to 80 and 80 to 150 soil layers and ranged from 2.69 to 1.49 .

TREe ReSPONSES TO DEFICIT IRRIGATION. The impact of water deficits on tree performance may be evaluated in terms of effects on fruit growth, photosynthetic rate, and yield. Fig. 4 depicts fruit growth and photosynthetic responses of the trees in absolute terms and relative to the fully irrigated control. Fruit volume was not affected until after 20 July when it started to decline in the LD trees and continued to expand but at a slower rate in the FD trees (Fig. 4a).

Photosynthesis rates in the LD and FD trees were statistically significantly different (ANOVA) from the $C$ trees on 19 and 22 July, respectively. As water stress became more severe, A fell to very low values; just before reirrigation, $\mathrm{A}$ values for the $\mathrm{C}, \mathrm{FD}$ and LD trees were $10.0,2.7$, and $0.8 \mu \mathrm{mol} \cdot \mathrm{m}^{-2} \cdot \mathrm{s}^{-1}$, respectively. There were differences in the A responses of the LD and FD trees; A decreased faster and to much lower values in LD than in FD because of the more severe tree water deficits that LD trees experienced as the deficit irrigation progressed (Fig. $1 \mathrm{~b}$ and c). Six days after reirrigation (5 Aug.), which was also the last measurement day, A had not fully recovered to initial values in either LD or FD trees (Fig. 4b). Although not presented here, measurements of stomatal conductance in C, FD, and LD depicted trends very similar to the photosynthetic responses, as has been shown in other studies (Marsal and Girona, 1997). Photosynthesis was much more affected by the water deficits than the final phase of fruit enlargement, which is illustrated by relatively steeper declines in the slopes of $\mathrm{FD} / \mathrm{C}$ and $\mathrm{LD} / \mathrm{C}$ during the 11-d period before rewatering (Fig. $4 \mathrm{c}$ ).

Fig. 4. Experimental data with time showing (a) fruit volume, (b) photosynthesis, and (c) their values relative to the control (C). Vertical bars are twice the mean SE for measurements through 19 July.

difference in available water, to be determined. Values of MXAWCF were calculated for all soil layers ( 0 to 20,20 to 50,50 to 80 , and 80 to $150 \mathrm{~cm}$ ). These continuous measurement-derived values for the
Table 1 presents yield information for the LD, FD and C trees. Water stress developed after tree fruit loads had already been defined by hand thinning to achieve nearly equal fruit loads. Fruit drop was similar for all treatments $(26.1,26.4$, and 30.0 fruit per tree in C, FD, and LD, respectively). Thus, yield impacts were primarily the result of stress effects on individual fruit size and weight. Individual fruit fresh weight was markedly affected in the LD trees

Table 1. Combined yield and yield components of 30 July and 5 Aug. harvests of eight trees each in the control and field and two lysimeter trees.

\begin{tabular}{lcccccc}
\hline \hline & $\begin{array}{c}\text { Fruit } \\
\text { load } \\
\text { (no./tree) }\end{array}$ & $\begin{array}{c}\text { Fresh } \\
\mathrm{wt} \\
\text { (g/fruit) }\end{array}$ & $\begin{array}{c}\text { Fruit } \\
\text { dry wt } \\
\text { Harvest }\end{array}$ & $\begin{array}{c}\text { Fruit } \\
\text { fresh wt } \\
(\mathrm{kg} / \text { tree })\end{array}$ & $\begin{array}{c}\text { Fruit } \\
\text { dry wt } \\
(\mathrm{kg} / \mathrm{tree})\end{array}$ & $\begin{array}{c}\text { Dry } \\
\text { matter } \\
(\% \mathrm{by} \mathrm{wt})\end{array}$ \\
\hline Control & $248 \mathrm{a}^{2}$ & $141 \mathrm{a}$ & $21.5 \mathrm{a}$ & $34.9 \mathrm{a}$ & $5.29 \mathrm{a}$ & $15.1 \mathrm{a}$ \\
Field & $255 \mathrm{a}$ & $131 \mathrm{a}$ & $21.6 \mathrm{a}$ & $32.8 \mathrm{a}$ & $5.39 \mathrm{a}$ & $16.5 \mathrm{~b}$ \\
Lysimeter & $283 \mathrm{a}$ & $97 \mathrm{~b}$ & $16.4 \mathrm{~b}$ & $27.1 \mathrm{a}$ & $4.59 \mathrm{a}$ & $17.0 \mathrm{~b}$
\end{tabular}

${ }^{\mathrm{z}}$ Numbers not followed by the same letter are statistically different using Duncan's multiple range test at $P=0.05$. Lack of third replication in the lysimeter treated as missing variable in ANOVA. 
Table 2. Fruit size distribution based on fruit diameter (cheek to cheek, mm) and expressed as percentages of total fruit harvested on 30 July and 5 Aug. for eight trees each in the control and field and the two lysimeter trees.

\begin{tabular}{lccccccc}
\hline & \multicolumn{5}{c}{ Fruit size $(\mathrm{mm})$} \\
\cline { 2 - 7 } Harvest & $<57.6$ & $57.6-63.1$ & $63.2-67.4$ & $67.5-70.4$ & $70.5-73.5$ & $73.6-77.6$ & $>77.7$ \\
\hline Control & $6.85 \mathrm{a}^{\mathrm{z}}$ & $6.73 \mathrm{a}$ & $24.7 \mathrm{a}$ & $22.5 \mathrm{a}$ & $15.5 \mathrm{a}$ & $15.2 \mathrm{a}$ \\
Field & $8.12 \mathrm{a}$ & $8.92 \mathrm{a}$ & $26.3 \mathrm{a}$ & $24.4 \mathrm{a}$ & $17.0 \mathrm{a}$ & $10.9 \mathrm{a}$ & $4.35 \mathrm{a}$ \\
Lysimeter & $34.3 \mathrm{~b}$ & $35.6 \mathrm{~b}$ & $28.6 \mathrm{a}$ & $10.1 \mathrm{~b}$ & $1.33 \mathrm{~b}$ & $0 \mathrm{~b}$ & $0 \mathrm{a}$ \\
\hline
\end{tabular}

${ }^{\mathrm{z}}$ Numbers not followed by the same letter are statistically different using Duncan's multiple range test at $P=0.05$. Lack of third replication in the lysimeter treated as missing variable in ANOVA.

but not significantly reduced $(6 \%)$ in the FD trees. There was significantly higher fruit dry matter content in both LD and FD but individual fruit dry weight was lower only in the LD trees (Table 1).

The smaller fruit in the LD trees produced a much different fruit size distribution, with almost no fruit $>70.5$ to $73.5 \mathrm{~mm}$ diameter, while $32 \%$ and $40 \%$ of the fruit in FD and $\mathrm{C}$ were $>70.5$ to $73.5 \mathrm{~mm}$ diameter, respectively (Table 2). While there was little impact of deficit irrigation on individual fruit weight in the FD trees, there was a trend that suggested smaller percentages of large fruit (Table 2).

INDICATOR SENSITIVITY TO DEFICIT IRRIGATION. To evaluate the differences in sensitivity among all indicators, we performed regression analyses of the relative values (FD/C and $\mathrm{LD} / \mathrm{C}$ ) of each indicator measured during the first $10 \mathrm{~d}$ of the deficit irrigation period (Table 3). Relationships were developed using only those sampling dates where all measurements were taken. Statistical significance was established based on differences among slopes using paired regression coefficient comparisons and the $\mathrm{F}$ distribution for $P>0.05$. The MXAWCF of the LD and FD trees declined more rapidly than the other indicators measured. The next most sensitive indicators were those derived from trunk diameter fluctuations, particularly the MNTD (Table 3). The plant $\Psi$ indicators were less sensitive than MXAWCF, MDS, and MNTD. There were no statistically significant differences among the plant $\Psi$ indicators. Finally, A in the FD trees was the least sensitive indicator, hardly being affected during the first 10-d period following the onset of deficit irrigation. In the LD trees, A was more affected; its absolute slope was similar to those of the plant $\Psi$ indicators.
While there were quantitative differences between the relative sensitivity responses in the LD and FD trees, the continuously derived soil and trunk diameter parameters were the most sensitive in both cases. Based on the statistical differences among slopes, the following sensitivity ranking may be established for the FD trees: MXAWCF > MNTD > MDS > stem $\Psi=$ leaf $\Psi=$ MXTD $=$ predawn leaf $\Psi>A$. The ranking for the $\mathrm{LD}$ trees is: MXAWC $>$ MNTD $>$ MDS $>$ MXTD $>$ stem $\Psi=\mathrm{A}=$ predawn leaf $\Psi=$ leaf $\Psi$.

\section{Discussion}

RELATIVE SENSITIVITY OF INDICATORS FOR EARLY STRESS DETECTION. This experiment induced the development of water deficits in peach trees by applying irrigation at rates below the potential consumptive use. Such a situation may occur inadvertently in orchard irrigation but can be avoided if the manager has access to relevant information related to soil or plant water status. This traditionally has involved discrete measurements which were usually compared with threshold values. The data from this study show that parameters only available with continuous monitoring are generally more sensitive to the onset of water deficits than the discrete measurements.

The first detectable response to the deficit irrigation was a marked increase in the maximum fluctuations of soil water content soon followed by an increase in the trunk diameter fluctuations (Figs. 2a and 3a). The latter is consistent with Hughet et al. (1992)

Table 3. Slopes, intercepts, and correlation coefficients for first order relationships between the indicated measurement relative to the fully irrigated control and time within the first $10 \mathrm{~d}$ after the onset of deficit irrigation. Relationships were developed using only those sampling dates where all measurements were taken.

\begin{tabular}{|c|c|c|c|c|}
\hline Harvest & $\begin{array}{c}\text { Indicator } \\
\text { measurement }\end{array}$ & $\begin{array}{l}\text { Absolute } \\
\text { slope }\end{array}$ & $\begin{array}{c}\text { Y-axis } \\
\text { intercept }\end{array}$ & $\begin{array}{l}\text { Correlation } \\
\text { coefficient }\end{array}$ \\
\hline \multirow[t]{8}{*}{ Field grown } & MXAWCF & $0.615 \mathrm{a}^{\mathrm{z}}$ & 6.37 & 0.650 \\
\hline & MNTD & $0.225 \mathrm{~b}$ & 0.87 & 0.918 \\
\hline & MDS & $0.101 \mathrm{c}$ & 1.01 & 0.965 \\
\hline & Stem $\Psi$ & $0.042 \mathrm{~d}$ & 1.09 & 0.869 \\
\hline & Leaf $\Psi$ & $0.024 \mathrm{~d}$ & 1.02 & 0.899 \\
\hline & MXTD & $0.021 \mathrm{~d}$ & 1.14 & 0.046 \\
\hline & Predawn Leaf $\Psi$ & $0.017 \mathrm{~d}$ & 1.06 & 0.863 \\
\hline & A & $0.002 \mathrm{e}$ & 0.83 & 0.994 \\
\hline \multirow[t]{8}{*}{ Lysimeter } & MXAWCF & $1.223 \mathrm{a}$ & 12.55 & 0.782 \\
\hline & MNTD & $0.601 \mathrm{~b}$ & 0.94 & 0.942 \\
\hline & MDS & $0.224 \mathrm{c}$ & 0.85 & 0.901 \\
\hline & MXTD & $0.149 \mathrm{~d}$ & 0.26 & 0.724 \\
\hline & Stem $\Psi$ & $0.049 \mathrm{e}$ & 0.94 & 0.759 \\
\hline & A & $0.039 \mathrm{e}$ & 1.13 & 0.708 \\
\hline & Predawn Leaf $\Psi$ & $0.028 \mathrm{e}$ & 0.91 & 0.644 \\
\hline & Leaf $\Psi$ & $0.023 \mathrm{e}$ & 1.05 & 0.911 \\
\hline
\end{tabular}

${ }^{\mathrm{z}}$ Numbers no followed by the same letter are statistically different at $P=0.05$ based on comparison of paired regression coefficients. 
who found that trunk diameter fluctuations increased as water stress became more severe in peach trees and So et al. (1979) who reported that the stem diameter fluctuations of corn increased well before the leaf $\Psi$ diverged from fully irrigated control values. Among the indicators based on discrete observations, stem $\Psi$ was first to diverge in the FD trees; relative stem $\Psi$ departed from unity at about the same time as relative MDS (Fig. 3a and b). Both relative predawn and midday leaf $\Psi$ departed from unity at a slower rate. This agrees with the observations made in field-grown almond and prune by Shackel et al. (1997) where stem $\Psi$ was generally more sensitive to water deficits than other measures of plant water status. One limitation of stem $\Psi$ is the difficulty in detecting small differences, such as those in the early stress phase due to measurement noise (Fig. 1c).

It is generally accepted that $\mathrm{g}_{\mathrm{s}}$ and A are not very sensitive to moderate water deficits (Bradford and Hsiao, 1982). Despite the limited number of A and gs measurements in this work, we conclude that such indicators were not as sensitive as those based on measurement of plant water status (Table 3), confirming the results of Girona et al. (1993) obtained in another peach variety at the same location.

Performance OF SENSORS FOR THE CONTINUOUS MONITORING OF SOIL WATER AND TRUNK DIAMETER. The parameters derived from the continuous monitoring of soil water and of trunk diameter hold promise as early stress detectors for precision irrigation scheduling. The magnitude of the differences observed in relative MXAWCF following the first $3 \mathrm{~d}$ of underirrigation (Figs. 2a and 3a) suggest that MXAWCF can be a sensitive indicator of the onset of irrigation deficits. We believe that the underlying causes for the large fluctuations in available soil water in both LD and FD were related to the high rooting densities near the soil surface under microirrigation which cause rapid water depletion in those areas when underirrigation occurs. As the upper soil layers were depleted in the days following the onset of deficit irrigation, the MXAWCF shifted to lower soil levels and its magnitude decreased substantially (Figs. 2a and 3a) as soil water extraction took place over a much larger soil depth (data not shown). Thus, MXAWCF is a relatively poor stress indicator after soil water extraction moves to lower parts of the profile.

The soil water data collected in this experiment suggest that fluctuations in the measurement, rather than the specific values of water content or potential, are most important in detecting irrigation deficits. The several fold differences in MXAWCF relative to $\mathrm{C}$ consistently observed in both LD and FD (Figs. 2a and 3a) should encourage further research to establish specific guidelines for using soil water oscillations measured with any of the instruments available for irrigation management (Green and Topp, 1992).

Among the several parameters that can be derived from trunk diameter monitoring, the MNTD exhibited the greatest relative differences in both LD and FD (Figs. 2a and 3a). Huguet et al. (1992) suggested MDS as the preferred trunk-monitored stress indicator although they did not report MNTD values. Our work also showed MDS to be quite sensitive to underirrigation; there was a 2-fold difference in MDS between LD and C $5 \mathrm{~d}$ after the onset of the experiment which increased thereafter (Fig. 2a). Lesser differences were observed for MXTD, probably because of the lower rates of trunk growth during stage III fruit growth in peaches (Li et al., 1989).

Several authors have associated changes in stem diameter with variations in water status (Klepper et al., 1971; Simonneau et al., 1993; Urban et al., 1994). Part of the change in trunk diameter is associated with secondary growth (Simonneau et al., 1993) but on a diurnal basis, most of the oscillations correlate well with changes in trunk water status and they are affected by atmospheric factors that determine the evaporative demand (Hinckley and Bruckerhoff,
1975). The oscillations in trunk diameter are apparently caused by the shrinkage and swelling of the external tissues (phloem, cambium and bark) with little contribution from the xylem, according to one report in apple trees (Brough et al., 1986). However, more work needs to be done to determine the anatomical compartments or the types of tissues that contribute to trunk water content oscillations.

DIFFERENTIAL RESPONSES OF LYSIMETER AND FIELD-GROWN TREES TO DEFICIT IRRIGATION. The LD and FD trees exhibited dissimilar behavior almost immediately following the onset of deficit irrigation. The MXAWCF values in LD were much more pronounced than in FD (Figs. 2a and 3a) as were the trunk diameter fluctuations (Fig. 1a). Differences in stress indicators between the LD and FD trees increased with time to the point that by the end of the drying cycle, stem $\Psi$ in LD was $0.5 \mathrm{MPa}$ lower than that in FD (Fig. 1c) and $\mathrm{A}$ in LD was only one third of the value in FD (Fig. 4b). These differences in behavior were apparently related to the lower effective water storage capacity of the lysimeter relative to the field condition. Both neutron probe and capacitance sensors showed no root extraction below $80 \mathrm{~cm}$ in the lysimeter while there was substantial depletion at $180 \mathrm{~cm}$ in the FD trees (data not shown). While the size and appearance of the LD trees were similar to those in the surrounding orchard, their root system was restricted to a smaller soil volume in all three dimensions_-in the tree row, across the tree row, and with depth. This resulted in a much faster rate of development and ultimately a greater magnitude of stress in the lysimeter.

Limited root development in the lysimeter was due to both the physical boundaries of the lysimeter itself and, most probably, high mechanical resistance generated by artificially packing the subsoil in the lysimeter to the high bulk density $\left(1.64 \mathrm{~g} \cdot \mathrm{cm}^{-3}\right)$ of the surrounding field soil. Soil water deficits and soil compaction are known to negatively affect plant physiological processes without apparent effects in shoot water relations, particularly in situations of confined root systems (Passioura, 1994). Such responses are apparently mediated by growth regulators produced in the root system and transported to the shoot where they may reduce expansive growth or induce stomatal closure, while the shoot water status is unaffected (Passioura, 1994). Apple trees with split-root systems growing in containers have exhibited such behavior (Jones, 1998). Peach trees subjected to different irrigation regimes had similar leaf water $\Psi$ while differing in $\mathrm{g}_{\mathrm{s}}$ (Fereres and Goldhamer, 1990). We anticipated that the LD and FD trees would have similar shoot water status but that the LD trees would have reduced physiological activity because of their confined root systems. However, the differential response of the LD trees was primarily related to the faster rate of development and to the more severe level of shoot water stress as shown by the steeper decline in all the shoot $\Psi$ measurements (Fig. 1b and c). Therefore, no indirect evidence of root signals (Passioura, 1994) was found in the present study.

The behavior of LD during recovery also differed from that of FD but in this phase, the LD trees recovered faster than the FD trees (Figs. $2 \mathrm{~b}$ and $3 \mathrm{~b}$ ). The LD trees achieved water potentials similar to those of the $\mathrm{C}$ trees just $2 \mathrm{~d}$ after rewatering, while the FD trees never fully recovered their water status even after 2 weeks of full irrigation. This differential response was associated with the different irrigation systems of LD and FD and also presumably with the different degree of root system confinement in each situation. The emitters in the lysimeter applied the same amount of water to a much smaller area than the microsprinklers in FD and thus wetted a larger fraction of the root zone. Girona et al. (1993) showed, for the same soil, the difficulty in refilling the profile of a deep rooted tree following the dry down period during a regulated deficit irrigation 
program. The differences in recovery between FD and LD emphasize the risks of underirrigation early in the season and the obstacles to alleviating stress in a deep profile with a low infiltration rate.

The rapid rate and more severe magnitudes of plant water deficits in LD yielded much smaller fruit at harvest. The minimal effects on fruit growth (Fig. 4a) and harvested fruit size (Tables 1 and 2) in FD were directly related to the more expansive size of the root zone (Passioura, 1994), the slower rate of development of water stress, and the relatively moderate level of stress achieved in this treatment. Fruit growth during stage III in peaches is caused by cell expansion and this reproductive aspect of growth may be less sensitive to water deficits than is vegetative growth during this period (Berman and DeJong, 1996; Li et al., 1989).

In conclusion, the sensors for continuous monitoring generated information on tree behavior that correlated well with established physiological parameters related to tree water status. With measurements that are continuously recorded, it is possible to glean parameters associated with the oscillations in soil water content and trunk diameter; parameters that cannot be generated with discrete measurements. In general, the indicators based on these oscillations were more sensitive than discrete observations in detecting the beginning of water deficits and reflecting their magnitude during the stress period. Analysis of the continuous records offers a more dynamic picture of events related to irrigation management and therefore holds promise for increasing the precision of irrigation decision-making.

\section{Literature Cited}

Berman, M.E. and T.M. DeJong. 1996. Water stress and crop load effect on fruit fresh and dry weights in peach (Prunus persica). Tree Physiol. 16(10):859-864

Bradford, K.J. and T.C. Hsiao. 1982. Physiological responses to moderate water stress, p. 264-312. In: O.L. Lange, P.S. Nobel, C.B. Osmond, and H. Ziegler (eds.). Physiological ecology II. Encyclopedia of plant physiology (NS vol. 12B). Springer-Verlag, New York.

Brough, D.W., H.G. Jones, and J. Grace. 1986. Diurnal changes in water content of the stems of apple trees, as influenced by irrigation. Plant Cell Environ. 9:1-7.

Dalton, F.N. 1992. Development of time-domain reflectometry for measuring soil water content and bulk soil electrical conductivity, p. 143-167. In: G.C. Topp et al. (eds.). Advances in measurement of soil physical properties: Bringing theory into practice. Soil Sci. Soc. Amer., Madison, Wis., Spec. Publ. 30.

Fereres, E. and D.A. Goldhamer. 1990. Deciduous fruit and nut trees, p. 987-1017. In: B.A. Stewart and D.R. Nielsen (eds.). Irrigation of agricultural crops. Amer. Soc. Agron., Madison, Wis. Monogr. 30.

Girona, J., M. Mata, D.A. Goldhamer, R.S. Johnson, and T.M. DeJong. 1993. Patterns of soil and tree water status and leaf functioning during regulated deficit irrigation scheduling in peach. J. Amer. Soc. Hort. Sci. 118(5):580-586.

Gowing, D.J.G., W.J. Davies, and H.G. Jones. 1990. A positive root sourced signal as an indicator of soil drying in apple. Malus $\times$ domestica Borkh. J. Expt. Bot. 41:1535-1540.

Green, R.E. and G.C. Topp. 1992. Survey of use of field methods for measuring soil hydraulic properties, p. 281-288. In: G.C. Topp et al. (eds.). Advances in measurement of soil physical properties: Bringing theory into practice. Soil Sci. Soc. Amer., Madison, Wis., Spec. Publ. 30.

Grimes, D.W., R.J. Miller, and P.L. Wiley. 1975. Cotton and corn root development in two field soils of different strength characteristics. Agron. J. 67:519-523.

Grimes, D.W. and H. Yamada. 1982. Relation of cotton growth and yield to minimum leaf water potential. Crop. Sci. 22:134-139.
Hinckley, T.M. and D.N. Bruckerhoff. 1975. The effects of drought on water relations and stem shrinkage of Quercus alba. Can. J. Bot. 53:6272.

Hsiao, T.C. 1990. Measurements of plant water status, p. 243-279. In: B.A. Stewt and D.R. Nielsen (eds.). Irrigation of agricultural crops. Amer. Soc. Agron., Madison, Wis. Monogr. 30.

Huck, M.G. and B. Klepper. 1976. Water relation of cotton. II. Continuous estimates of plant water potential from stem diameter measurements. Agron. J. 69:593-597.

Huguet, J.G, S.H. Li, J.Y. Lorendeau, and G. Pellous. 1992. Specific micromorphometric reactions of fruit trees to water stress and irrigation scheduling automation. J. Hort. Sci. 67(5):631-640.

Jones, H.G. 1998. Stomatal control of photosynthesis and transpiration. J. Expt. Bot. 49(SI):387-398.

Klepper, B., V.D. Browning, and H.M Taylor. 1971. Stem diameter in relation to plant water status. Plant Physiol. 48:683-685.

Ley, T.W. 1994. An in-depth look at soil water monitoring and measurements tools. Irr. J. 44:8-20.

Li, S.H., J.G. Huguet, and C. Bussi. 1989. Irrigation scheduling in mature peach orchard using tensiometers and dendrometers. Irr. Drainage Systems $3: 1-12$.

Marsal, J. and J. Girona. 1997. Relationship between leaf water potential and gas exchange activity at different phenological stages and fruit loads in peach trees. J. Amer. Soc. Hort. Sci. 122(3):415-421.

Martin, D.L., E.C. Stegman, and E. Fereres. 1990. Irrigation scheduling principles, p. 155-203.In: G.J.Hoffman, T.A. Howell, and K.H. Solomon (eds.). Management of farm irrigation systems. Amer. Soc. Agr. Eng., Madison, Wis.

McDonnell, J.J. 1993. Electronic versus fluid multiplexing in recording tensiometer systems. Trans. Amer. Soc. Agr. Eng. 36(2):459-462.

Paltineau I.C. and J.L. Starr. 1997. Real-time soil water dynamics using multisensor capacitance probes: Laboratory calibration. Soil Sci. Soc. Amer. J. 61(6):1576-1585.

Passioura, J.B. 1994. The yield of crops in relation to drought, p. 343-359. In: K.J. Boote, J.M. Bennett, T.R. Sinclair, and G.M. Paulsen (eds.). Physiology and determination of crop yield. Amer. Soc. Agron., Madison, Wis.

Phene, C.J., G.J. Hoffman, T.A. Howell, D.A. Clark, R.M. Mead, R.S. Johnson, and L.E. Williams. 1991. Automated lysimeter for irrigation and drainage control. Lysimeters for evapotranspiration and environmental measurements. Amer. Soc. Civ. Eng., Irr. Div. Meeting, Honolulu, Hawaii. p. 28-36.

Savage, M.J., H.H. Wiebe, and A. Cass. 1983. In situ field measurement of leaf water potential using thermocouple psychrometers. Plant Physiol. 73:609-613.

Seyfried, M.S. 1993. Field calibration and monitoring of soil-water content with fiberglass electrical resistance sensors. Soil. Sci. Soc. Amer. J. 57(6):1432-1436.

Shackel, K.A., H. Ahmadi, W. Biasi, R. Buchner, D. Goldhamer, S. Gurusinghe, J.Hasey, D. Kester, B. Krueger, B.Lampinen, G. McGourty, W. Micke, E. Mitcham, B. Olson, K. Pelletrau, H. Philips, D. Ramos, L. Schwankl, S. Sibbett, R. Snyder, S. Southwick, M. Stevenson, M. Thorpe, S. Weinbaum, and J. Yeager. 1997. Plant water status as an index of irrigation need in deciduous fruit trees. HortTechnology 7(1):23-29.

Simonneau, T., R. Habib, J.P. Goutouly, and J.G. Huguet. 1993. Diurnal changes in stem diameter depend upon variations in water content: Direct evidence in peach trees. J. Expt. Bot. 44(260):615-621.

Snyder, R.L. and W.O. Pruitt. 1989. Reference evapotranspiration, p. 24 27. In: D.A. Goldhamer and R.L. Snyder (eds.). Irrigation scheduling: A guide for efficient on-farm water management. Univ. Calif. Div. Agr. Nat. Res. Publ. 21454.

So, H.B., D.C. Reicosky, and H.M Taylor. 1979. Utility of stem diameter changes as predictors of plant canopy water potential. Agron. J. 71:707713.

Urban, L., C. Febret, and L. Barthelemy. 1994. Interpreting changes in stem diameter in rose plants. Physiol. Plant. 92:668-674. 